\title{
Global carbon surcharge for the reduction of anthropogenic emission of carbon dioxide
}

\author{
André Thess $^{1,2^{*}}$, Martin Klein ${ }^{1}$, Kristina Nienhaus ${ }^{1}$ (D) and Thomas Pregger $^{1}$ (D)
}

\begin{abstract}
Background: Many governments take the view that voluntary national targets to reduce greenhouse gas emissions are sufficient to avoid negative climate effects. In the absence of independent verification, however, pledges are unlikely to be sufficient for a rapid and strong reduction of emissions. It is often claimed that a global carbon tax could be an effective instrument. However, such a tax is difficult to set and to collect, especially in countries with poor administrative infrastructure.

Results: Here, we formulate and discuss a novel approach, the Global Carbon Surcharge (GCS), that mimics a carbon tax but does not require tax collection by governments. We define GCS as a requirement or a voluntary commitment encompassing all companies extracting carbon-carrying raw materials, namely coal, oil, gas and limestone, with the aim to burden their extraction with costs proportional to their carbon intensity. GCS mandates all companies to store these materials immediately after mining for a given period of time in the vicinity of the production site. Thereby, GCS generates additional costs that propagate through all sectors of the global economy. We elucidate how the investment costs for the storage infrastructure translate into surcharges on the raw materials.

Conclusions: We show that by a proper choice of the storage time and the size of the storage unit, GCS becomes equivalent to a carbon tax in the range between 50 and $100 €$ per ton of $\mathrm{CO}_{2}$ that is assumed to be necessary for the transition to a carbon-neutral energy system. An attractive feature of GCS is that it can be verified, in particular by citizens themselves, using publicly available satellite data. Finally, if compulsory storage is coupled to blockchainbased smart contracts and a mandatory (expensive) mining of cryptocurrency, GCS can be operated without governmental protectionism, corruption and fraud. However, the main uncertainties of the GCS approach lie in the substantial expansion of infrastructure and the fact that the induced price effects must be sufficient to achieve a rapid and far-reaching substitution of fossil fuels.
\end{abstract}

Keywords: Global carbon surcharge, Climate policy, Decarbonization, Carbon pricing

\section{Background}

Mitigating climate change is a grand challenge of the twentyfirst century [1-7]. The current approach to accomplish this task is embodied in the Paris Agreement [1] under which each country sets voluntary national targets for the reduction of the emissions of $\mathrm{CO}_{2}$ and other greenhouse gases (GHG). However, such agreements alone have drawbacks. If there are no financial penalties against countries who fail to meet their targets, the implemented agreements can be ineffective.

\footnotetext{
*Correspondence: andre.thess@dlr.de

'German Aerospace Center (DLR), Institute of Engineering Thermodynamics,

Pfaffenwaldring 38-40, 70569 Stuttgart, Germany

${ }^{2}$ University of Stuttgart, Pfaffenwaldring 31, 70569 Stuttgart, Germany
}

Furthermore, governments can withdraw from the Paris Agreement, as the announcement by the US administration $[8,9]$ has shown. Finally, there is no explicit incentive for governments to meet the targets in a cost-efficient way.

Market-based instruments such as carbon trading schemes and carbon taxes $[3,10,11]$ promote an efficient allocation of resources and lead to economic incentives for decarbonization. However, carbon trading does not necessarily cover all sectors and requires extensive administrative efforts for small and decentralized sources of GHG emissions. Carbon taxes do not necessarily cover all sectors either. Moreover, they are difficult to collect in countries with weak governance, and the use of the tax 
income in such countries is not necessarily to the benefit of the people.

Current approaches, in which international climate agreements are essentially voluntary, have little prospect of slowing climate change if freeriding is widespread. To avoid free riders that occur when a party receives the benefits of a public good without sharing the costs, other researchers have already developed polycentric $\mathrm{CO}_{2}$ surcharge systems that do not rely on international global agreements that need to be transposed into national law.

Spreng et al. [12] propose a new type of climate insurance for $\mathrm{CO}_{2}$. In this system, fossil fuels can be 'insured'. A label would then indicate whether products were produced with energy from insured fossil fuels or not. The premiums collected from this 'risk pool' would be used to adapt to climate change and to compensate for certain damages; in return, the producers of the insured fossil fuels would be protected against claims of liability for climate damage. Consumers could decide whether they prefer labelled or unlabelled products. Similarly, Nordhaus [13] argues for a so-called climate club, a new type of free-trade zone. Participating governments would be incentivized to pursue a strong climate policy as this would not lead to exclusion from the free-trade zone. Modelling results suggest that small trade penalties for non-participants can lead to more climate cooperation. However, it is difficult for such and other approaches to prove their effectiveness.

To overcome the drawbacks of existing schemes for the reduction of $\mathrm{CO}_{2}$ emissions, we formulate a conceptually simple economic model, the Global Carbon Surcharge (GCS), that increases the costs of carbon-carrying materials at the earliest possible stage of the value chain. It thereby creates economic incentives to decarbonize the energy systems and minimizes administrative efforts. In the present work, we investigate GCS as an exemplary thought experiment, without being able to go into the details of its practical implementation in a comprehensive manner. In particular, we are aware that the sole purpose of our concept is raising the cost of $\mathrm{CO}_{2}$ emissions and that it is therefore unlikely to be realized in its proposed form.

\section{Approach}

The majority of anthropogenic $\mathrm{CO}_{2}$ emission is due to the combustion of coal, oil and gas, and to a smaller extent due to the use of limestone (calcium carbonate, $\mathrm{CaCO}_{3}$ ) for the production of cement [14]. If a mechanism could render the extraction of these materials increasingly difficult, the prices for these four commodities would increase. Such economic signal would propagate through the global value chain and provide strong incentives for a decarbonization of the energy system.
We stipulate that the commodity $\mathrm{x}$ (where $\mathrm{x}$ stands for gas, oil, coal or limestone) is stored for a given period of time, denoted $n_{\mathrm{x}}$ [years], in the vicinity of the mining site, before it is released into the market. We further assume that the investment costs for the storage infrastructure are equal to $c_{\mathrm{x}}$ [in $€$ per ton of storage capacity], the lifetime of the infrastructure is $n$ [years] and the interest rate is $i$ [percent], and that the operating costs for the infrastructure are negligible in comparison with the investment costs.

As detailed in the 'Methods: model and data' section, we compute the surcharge $\mathrm{Cs}_{\mathrm{x}}$ [in $€$ per ton of $\mathrm{CO}_{2}$ ] that has to be added to the cost of each of the four materials in order to compensate for the depreciation of the storage infrastructure. This quantity shall be referred to as the Global Carbon Surcharge. We are particularly interested in the question under which conditions the GCS is equal to $75 € / \mathrm{t}$ [ $€$ per ton of $\mathrm{CO}_{2}$ ] assumed here to be a plausible benchmark of effectiveness in the wide range of estimates of social costs of $\mathrm{CO}_{2}$ emission $[15,16]$. In order to show the sensitivity of the results, we distinguish between more expensive small-scale and lowercost large-scale options and vary interest rate, storage time and lifetime of the storage infrastructure.

It should be made clear from the outset that the sole purpose of this measure is to make $\mathrm{CO}_{2}$ emissions more expensive without any other benefit. This distinguishes the present thought experiment from other concepts like the carbon tax.

\section{Methods: model and data Model}

Our model for the carbon surcharge $\mathrm{cs}_{\mathrm{x}}$ rests on the following assumptions: (1) A source of a carbon-carrying raw material $\mathrm{x}$ (coal, oil, gas, limestone) delivers a mass $m_{\mathrm{x}}$ [tons] per year. After combustion of gas, oil and coal or after calcination of limestone, a mass of $m$ [tons] $\mathrm{CO}_{2}$ is generated from each ton of raw material. For the present computation, we do not need the masses $m_{\mathrm{x}}$ and $m$ but only the carbon ratio $\alpha_{\mathrm{x}}=m / m_{\mathrm{x}}$. This parameter expresses how many tons of $\mathrm{CO}_{2}$ are generated from each ton of carbon-carrying material. (2) The raw materials are stored in a storage infrastructure with specific investment $\operatorname{costs} c_{\mathrm{x}}$ [Euro per ton], lifetime $n$ [years] and interest rate $i$ [percent] whose operating costs are negligible in comparison with the investment costs. (3) A mandatory storage time $n_{\mathrm{x}}$ [years] is assumed over which the raw material $x$ has to be kept in the storage infrastructure before it may be released for sale.

Under the given assumptions, the total capital cost of the storage infrastructure (per ton of storage capacity) can be calculated as $c_{\mathrm{x}} a_{\mathrm{n}, \mathrm{i}}$, where the annuity $a_{\mathrm{n}, \mathrm{i}}$ is given by the equation 


$$
a_{n, i}=\frac{(1+i)^{n} \times i}{(1+i)^{n}-1}
$$

The depreciation of the infrastructure appears as a surcharge to each ton of material for each storage cycle. The total number of storage cycles over the lifetime of the infrastructure is $n /\left(\mathrm{t}_{\mathrm{x}} / 365\right)$ or $n / n_{\mathrm{x}}$. Taking into account that one ton of material $\mathrm{x}$ is converted into $\alpha_{\mathrm{x}}$ tons of $\mathrm{CO}_{2}$, the desired result for the carbon surcharge is

$$
c s_{x}=\frac{n_{x} c_{x} a_{n, i}}{\alpha_{x}}
$$

This quantity is equivalent to the effective carbon surcharge in $€$ per ton of $\mathrm{CO}_{2}$ that would be induced by the proposed mechanism.

\section{General input data}

For our calculations, we use the following general input data: $\alpha_{\text {gas }}=2.98, \alpha_{\text {oil }}=3.21, \alpha_{\text {coal }}=2.5, \alpha_{\text {limestone }}=0.44$ (according to [17]), an assumed lifetime of the storage infrastructure of $n=10$ years and interest rates equal to $i=0 \%, 5 \%$ and $10 \%$.

\section{Data for large-scale storage infrastructure}

Natural large-scale storage solutions include all options where natural materials are used to confine the mined material. We use the following estimates for the specific investment costs $c_{x}$ based on expert judgments, available analyses (e.g., $[18,19])$ and own assumptions:

$\bigcirc$ Open-pit coal or limestone storage: $c_{\mathrm{c}}=1 € / \mathrm{t}$

Underground oil storage: $c_{\mathrm{o}}=1.1 € / \mathrm{t}$

$\bigcirc$ Underground gas storage salt cavern: $c_{\mathrm{g}}=5 € / \mathrm{t}$ to $35 € / \mathrm{t}$

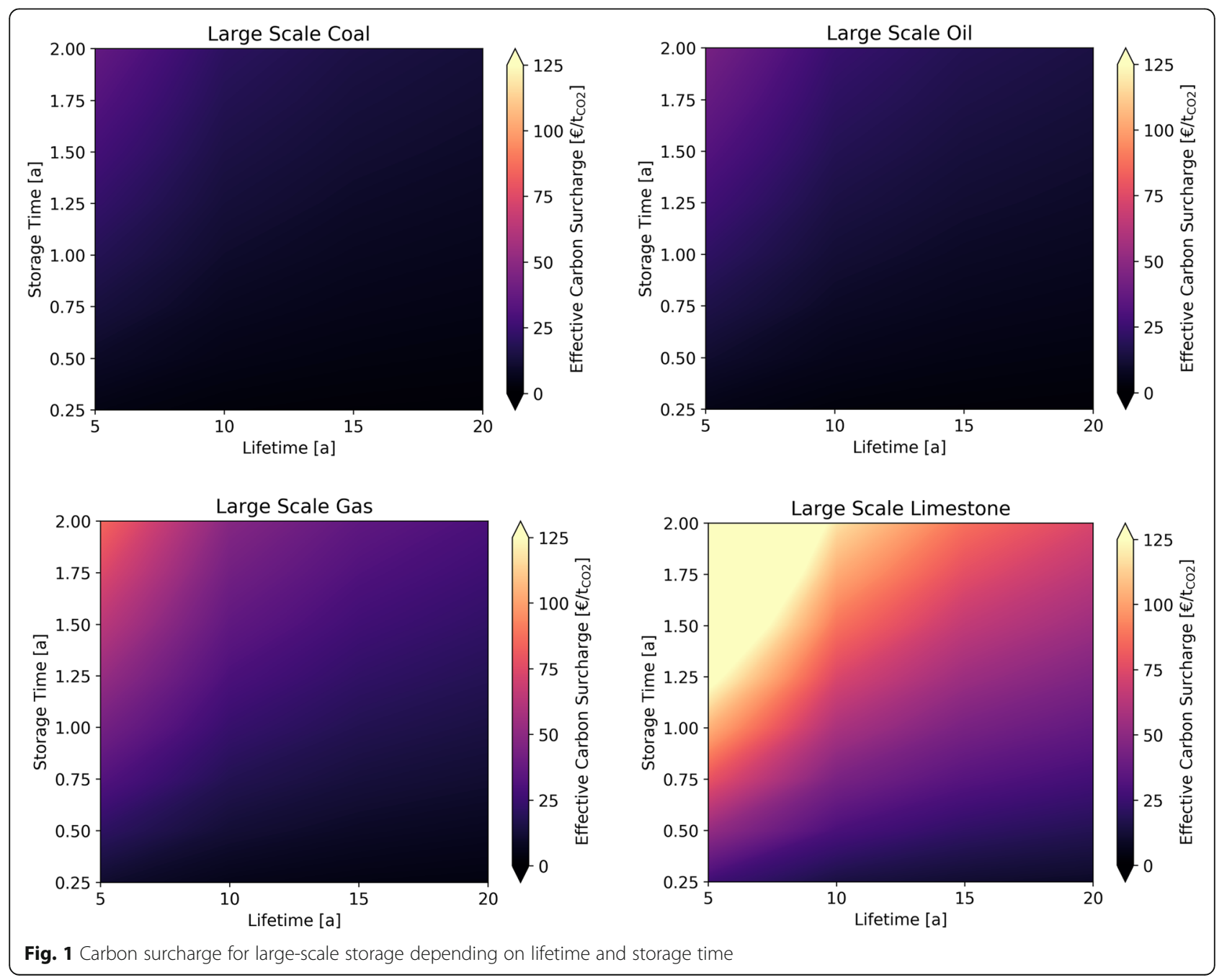


$\bigcirc$ Underground gas storage depleted gas reservoir: $c_{\mathrm{g}}=1 € / \mathrm{t}$ to $18 € / \mathrm{t}$

Artificial large-scale storage solutions include all options where the storage vessels are made of artificial materials. Our estimations are based on various industry expert interviews, business information (e.g., [20-22]) and own assumptions and amount to:

$\bigcirc$ Enclosed coal and limestone bunkers: $c_{\mathrm{c}}=200 € / \mathrm{t}$

Oil storage tanks (steel tanks): $c_{\mathrm{o}}=300 € / \mathrm{t}$

$\bigcirc$ Gas tank farms (pipe container, $70 \mathrm{bar}$ ): $c_{\mathrm{g}}=550 € / \mathrm{t}$

\section{Data for small-scale storage infrastructure}

The investment costs consist of investment in the wagon (approximately 100,000 €, estimation based on information from German manufacturers [23-25]), in the tracks (around 10,000 € per $10 \mathrm{~m}$ trackage derived from historic cost data for light railways) and the cost of steel containers that depends on the good (again average estimations derived from manufacturer's information [26, 27] and own assumptions):

Silo for pulverized coal and limestone: $c_{\mathrm{c}}=2200 € / \mathrm{t}$

Oil tank: $c_{\mathrm{o}}=1900 € / \mathrm{t}$

Gas tank (CNG, $200 \mathrm{bar}): c_{\mathrm{g}}=8900 € / \mathrm{t}$

Sensitivity tests were carried out with regard to storage time and lifetime of the storage infrastructure. The results of these calculations in terms of effective GCS are plotted in Figs. 1 and 2.

\section{Assessment of resource intensity}

As a benchmark, the resource intensities of the two most important materials of the built environment-concrete and steel-which would be needed to build the physical storage infrastructure are taken as an estimate for the additional emissions generated by GCS. As these
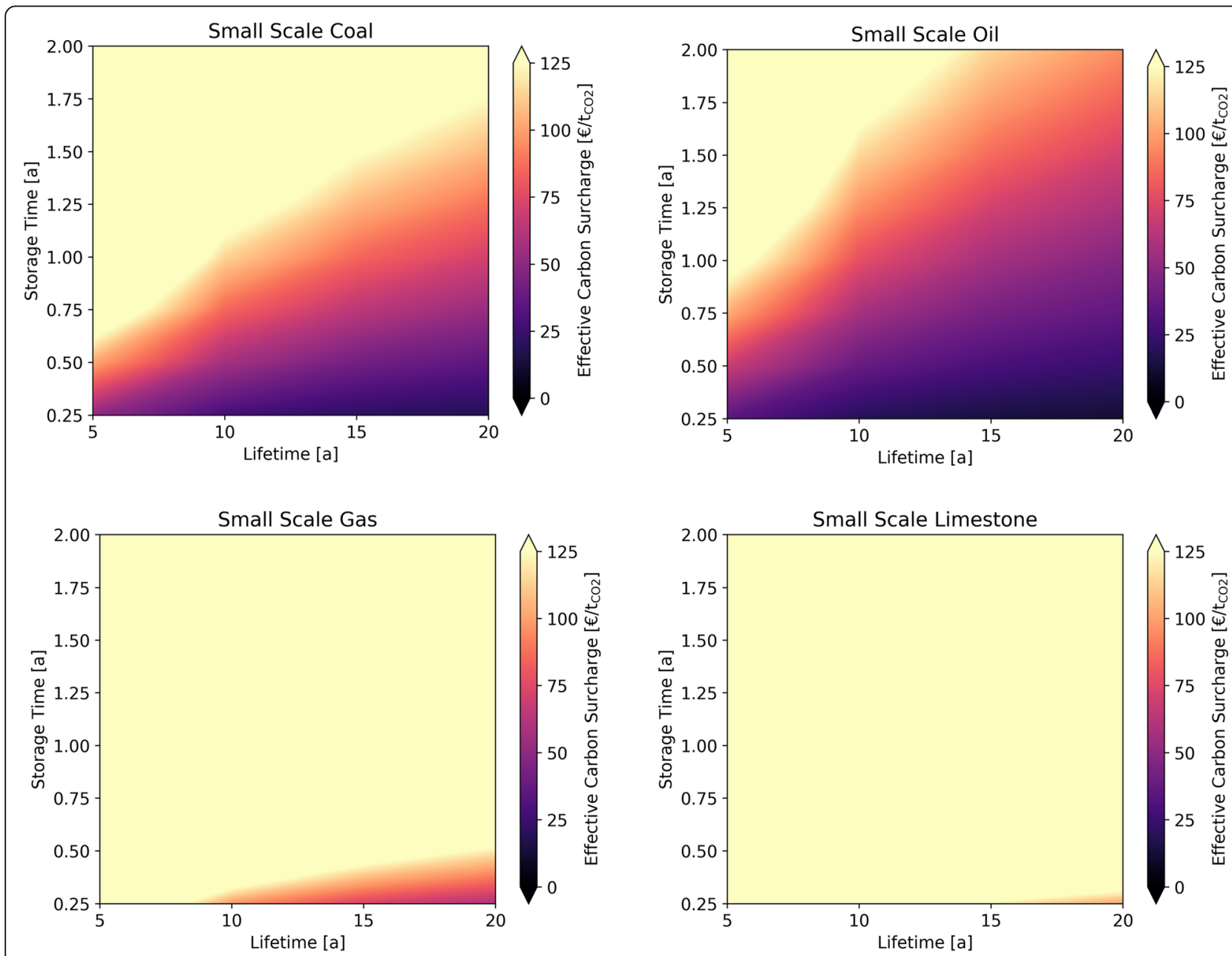

Fig. 2 Carbon surcharge for small-scale storage depending on lifetime and storage time 
materials carry embodied emissions, their usage by GCS would be the source of additional global warming. To reach a target surcharge cs, certain investments in materials have to be undertaken. As an upper estimate, we assume that the world market cost of concrete and steel would be the basis of the expenditures necessary to raise the effective carbon price. As cost values, we assume:

Steel: $c_{\mathrm{s}}=500 € / \mathrm{t}$

Concrete: $c_{\mathrm{co}}=43.5 € / \mathrm{t}$

From the ecoinvent database [28], we take global warming potentials (including pre-chain emissions) per ton of material $\mathrm{GWP}_{\mathrm{x}}$, with the following values:

Steel: $\mathrm{GWP}_{\mathrm{s}}=2.172 \mathrm{t}_{\mathrm{CO} 2 \mathrm{eq}} / \mathrm{t}$

Concrete: $\mathrm{GWP}_{\text {co }}=0.099 \mathrm{t}_{\mathrm{CO} 2 \mathrm{eq}} / \mathrm{t}$

The additional emissions $e$ can thus simply be derived from the targeted surcharge, the specific expenditure per ton of material $x$ and the specific impact as:

$$
e_{x}=\frac{\mathrm{cs}}{c_{x}} \mathrm{GWP}_{x}
$$

In addition, the following specifications were assumed for the estimation of material requirements and land use of standard goods wagons according to [23]: Oil and gas: 95 $\mathrm{m}^{3}$ volume, $\sim 16 \mathrm{~m}$ length, $17.6 \mathrm{t}$ dead weight. Solid materials: $82 \mathrm{~m}^{3}$ volume, $\sim 16 \mathrm{~m}$ length, $18.3 \mathrm{t}$ dead weight.

\section{Results}

We first analyse the results for large-scale storage, which we classify into natural and artificial. Natural large-scale storage includes all options where natural boundaries confine the mined material, whereas artificial storage refers to engineering constructions. With the estimates $c_{\text {coal }} \approx c_{\text {limestone }} \approx 1 € / \mathrm{t}$ for open pit storage, $c_{\text {oil }}=1.1 € / \mathrm{t}$ for underground oil storage in salt caverns, $10 € / \mathrm{t}<c_{\text {gas }}<$ $35 € /$ t for underground gas storage in salt caverns and 5 $€ / \mathrm{t}<c_{\text {gas }}<18 € / \mathrm{t}$ for underground gas storage in depleted gas reservoirs, we arrive at surcharges (per ton of $\mathrm{CO}_{2}$ ) in the range between $\mathrm{cs}_{\mathrm{x}}=0.1 € / \mathrm{t}$ and $\mathrm{cs}_{\mathrm{x}}=2 € / \mathrm{t}$. This is significantly smaller than the mentioned benchmark. It should also be noted that, for reasons of energy security, large-scale oil storage infrastructures have already been built in recent decades with low price effects.

Figure 3 (left) shows the carbon surcharge for artificial large-scale storage. In order to take into account future economic uncertainties, we plot the GCS for interest rates ranging from $i=0 \%$ to $i=10 \%$. The figure demonstrates that the carbon surcharge is a linearly increasing function of the storage time whose slope is inversely proportional to the carbon ratio $\alpha_{\mathrm{x}}$ defined in the 'Methods: model and data' section. Since $\alpha_{\text {limestone }}$ is significantly lower than that of the other materials, the carbon surcharge for limestone has a higher slope and is therefore better suited for GCS. Nevertheless, Fig. 3 (left) shows that all surcharges, except for limestone at high interest rate, remain below $75 € / t$ as long as the storage time is less than 2 years. Although we have neglected operating costs, which may generate higher values of the
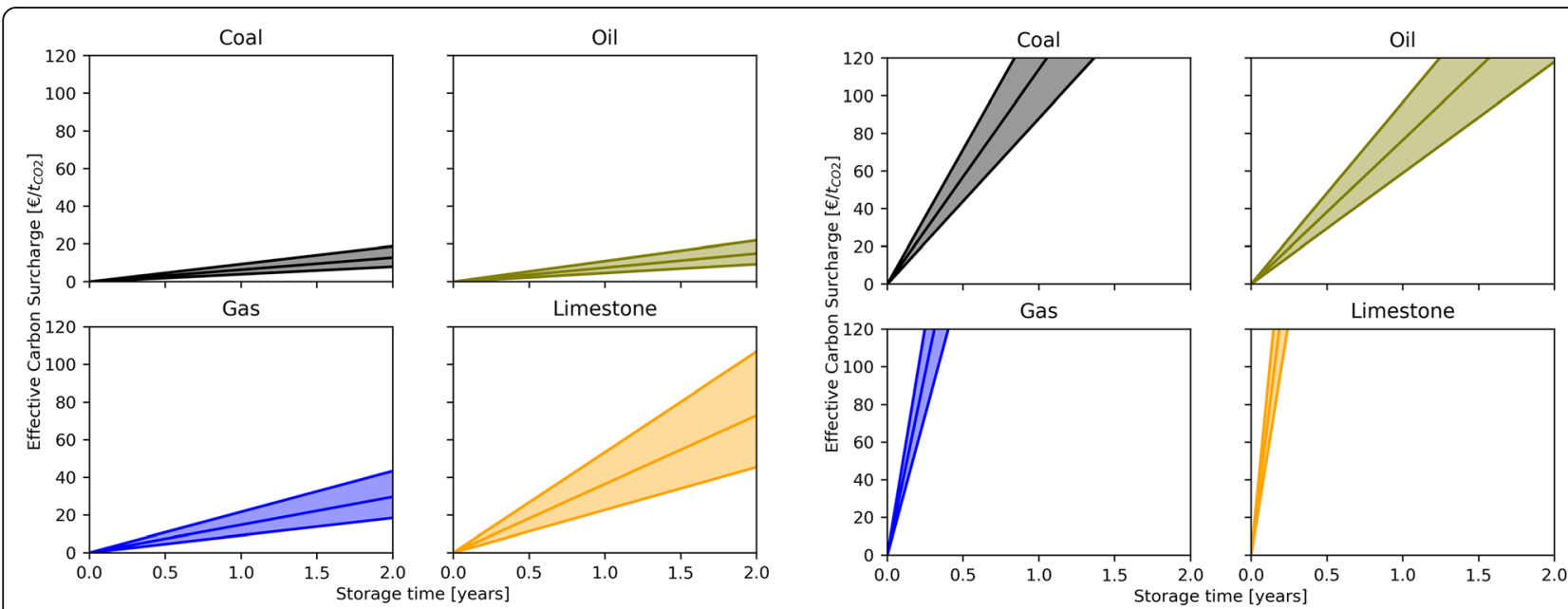

Fig. 3 Carbon surcharge for coal, oil, gas and limestone for different storage options as a function of the storage time. left: Storage in large-scale enclosed coal and limestone bunkers with $c_{\text {coal }}=c_{\text {limestone }}=200 € / \mathrm{t}$, in large steel storage tanks for oil with $c_{\mathrm{oil}}=300 € / \mathrm{t}$ and in gas tank farms with pipe containers ( 70 bar storage pressure) with $c_{\text {gas }}=550 € /$ t. right: Storage in small-scale storages (incl. container, wagon and tracks) with $c_{\text {coal }}=$ $c_{\text {limestone }}=2200 € / \mathrm{t}, c_{\mathrm{oil}}=1900 € / \mathrm{t}$ and $c_{\text {gas }}=8900 € / \mathrm{t}$. Lines are for interest rates $i=0 \%$ (lower line), $i=5 \%$ (middle line) to $i=10 \%$ (upper line) and for a lifetime of the storage infrastructure of $n=10$ years. The area between $i=0 \%$ and $i=10 \%$ is shaded to guide the eye. 


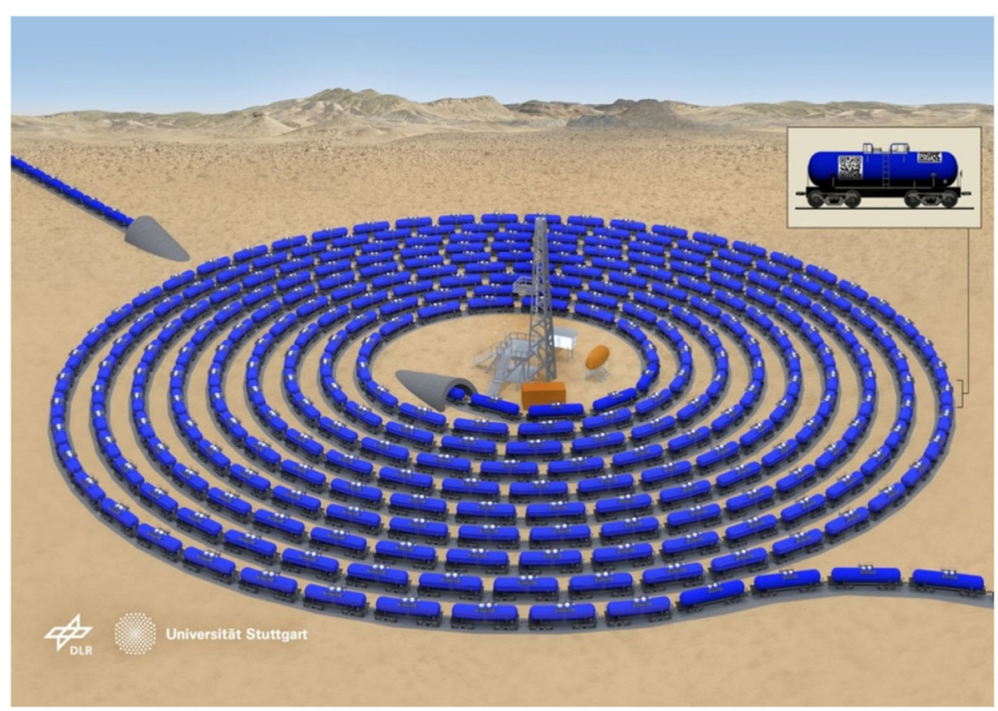

Fig. 4 Visualization of global carbon surcharge by small-scale oil storage. Conceptual representation of the storage of oil in the vicinity of an oil well using containers and railway cars

surcharge, we conclude that artificial large-scale storage is unlikely to be a feasible basis for GCS.

We next analyse a modified concept, referred to as small-scale storage. Here, we assume that the flow of all four carbon-carrying raw materials is discretized into standardized small portions that are easy to track. More specifically, we assume that after mining, the materials are filled into standard intermodal containers which are mounted on railway cars. As shown in the conceptual view in Fig. 4, the cars can be driven to the storage site and kept there for the required time. If the upper sides of the containers are equipped with a digital identifier in the form of a barcode or a QR code, the identity and position of the car can be tracked from space (see e.g., [29]) or by future high-altitude platforms [30]. The computed surcharge for small-scale storage is shown in Fig. 3 (right). The figure reveals that the higher investment costs for railway cars and containers as compared to the large-scale storage options translate directly into a higher slope of $\mathrm{Cs}_{\mathrm{x}}$ versus storage time. This implies that small-scale storage is suited to provide a surcharge in the range of $75 € / \mathrm{t}$.

Table 1 gives an overview of $\mathrm{cs}_{\mathrm{x}}$ for both large-scale and small-scale storage options. For a storage time of 1 year, all small-scale storage options lead to a surcharge that is higher than $75 € / t$. This indicates that small storage units and long storage times are the key to high values of $\mathrm{cs}_{\mathrm{x}}$. The last column of Table 1 shows the storage time necessary to obtain $\mathrm{Cs}_{\mathrm{x}}=75 € / \mathrm{t}$. The figures indicate that for the small-scale storage case, the required storage time is less than 1 year for all materials considered.

Table 1 Carbon surcharge for large-scale and small-scale storage options. For a given specific investment cost $c_{x}$ and carbon ratio $a_{x} . C S_{x}$ is the carbon surcharge under the assumption of a storage time of 1 year. $n_{x}$ is the storage time required for the carbon surcharge to be equal to $75 € / \mathrm{t}_{\mathrm{CO} 2}(n=10$ years and $i=5 \%$ is assumed throughout)

\begin{tabular}{|c|c|c|c|c|}
\hline & $c_{x}\left[€ / t_{x}\right]$ & $a_{x}\left[t_{\left.\mathrm{CO}_{2} / t_{x}\right]}\right.$ & $\mathrm{CS}_{\mathrm{x}}\left[€ / \mathrm{t}_{\mathrm{CO} 2}\right]$ at $n_{\mathrm{x}}=1$ year & $n_{\mathrm{x}}[$ months $]$ at $\mathrm{CS}_{\mathrm{x}}=75 € / \mathrm{t}_{\mathrm{CO} 2}$ \\
\hline Coal-large scale & 200 & 2.50 & 10.4 & 87 \\
\hline Limestone-large scale & 200 & 0.44 & 58.9 & 15 \\
\hline Oil_large scale & 300 & 3.21 & 12.1 & 74 \\
\hline Gas_large scale & 550 & 2.98 & 23.9 & 38 \\
\hline Coal—small scale & 2200 & 2.50 & 114 & 7.9 \\
\hline Limestone-small scale & 2200 & 0.44 & 648 & 1.4 \\
\hline Oil_small scale & 1900 & 3.21 & 77 & 11.7 \\
\hline Gas_small scale & 8900 & 2.98 & 387 & 2.3 \\
\hline
\end{tabular}




\section{Discussion}

We now briefly discuss the limitations of the presented model as well as the advantages and disadvantages of GCS over traditional methods for climate change mitigation.

As GCS is a conceptual thought experiment, its realization is elaborated only theoretically. In order to keep our model simple, we have neglected two aspects. First, we have confined our attention to the direct investment costs for the storage infrastructure because they can be described by a simple universal scaling law. We have neglected indirect investment costs (e.g., measures necessary for compliance with environmental regulations or other legislation) as well as operating costs. We have also ignored the risks of cost overruns [31] that are characteristic of large-scale construction projects. Taking into account these costs would increase $\mathrm{Cs}_{\mathrm{x}}$ significantly. Second, we assumed in our model that the lifetime $n$ and the storage time $n_{\mathrm{x}}$ are given parameters. As a consequence, the surcharge would drop after $n$ years because the investment costs have been recovered, but further costs may arise from maintenance and replacement after the lifetime of the storage facility. In the event that the storages are provided by leasing companies, additional costs may be incurred for logistics services. If GCS were to be implemented globally, $n_{\mathrm{x}}$ would have to be increased continuously so as to enforce a continuous expansion of the storage capacity and to make $\mathrm{Cs}_{\mathrm{x}}$ a monotonically increasing function of time. Moreover, the parameters $n_{\mathrm{x}}$ would have to be set in such a way that the surcharge per ton of $\mathrm{CO}_{2}$ is identical for all four materials.

Potential advantages of GCS are its impact across all economic sectors, no need for tax collection, the absence of tax revenues in countries with weak governance, the opportunity to publicly trace and verify the carbon storage using remote sensing and the possibility to organize GCS as a global agreement between citizens and firms with little or no governmental involvement.

Potential disadvantages of GCS are the high financial and resource expenditures for the theoretically drafted storage infrastructure, the non-uniformity of the storage cost due to differences in the material and labour cost between different countries, possible ecological damage, safety risks and land use, and large revenues for certain sectors like the construction and steel industries. The embodied emissions of the materials of the storage infrastructure (mainly steel and concrete) would be an additional source of GHG emission. We estimate that the expenditure on steel and concrete necessary to raise the effective carbon price would at maximum generate additional emissions between 0.14 and $0.31 \mathrm{t}$ of $\mathrm{CO}_{2}$-equivalent per ton of priced carbon for a surcharge of $75 € / t$, which would conversely reduce the available budget of remaining emissions. The use of infrastructure would be considerable in the case of small-scale storage. If we assume standard goods wagons more than 150 million units would be required to store the four considered commodities according to the assumed required storage time $n_{\mathrm{x}}$ shown in Table 1. The material requirements for the goods wagons are estimated at more than 2.7 billion metric tons (mainly steel, i.e. 1.7 times annual world steel production) and the land use at about $6500 \mathrm{~km}^{2}$, which is about $1 \%$ of the size of France. Assuming today's specific emissions of $1.83 \mathrm{t}$ of $\mathrm{CO}_{2}$ per ton of steel [32], the GCS approach would, in the worst-case scenario, cause an additional output from steel production equivalent to $12-15 \%$ of today's global $\mathrm{CO}_{2}$ emissions.

Finally, we wish to discuss our concept from a broader perspective. The artistic view expressed in Fig. 4 must not be taken literally. Nevertheless, it illustrates three key properties of GCS, namely the discretization of the global carbon stream into small parcels, the traceability of each individual parcel, e.g. from space, and the possibility to apply a controlled resistance to the mining of carbon-carrying materials.

We shall now explain how these features can be enhanced and improved by cryptographic tools. We have already pointed out that each container could be equipped with a QR code that allows satellites to trace them from space. In order to avoid any residual possibility of fraud, each container of coal could be additionally registered in a blockchain $[4,33]$. The data in the blockchain can be accessed by anyone through the Internet, and hence, each container can be traced by the general public from the instant of mining to its injection into the coal market. Blockchain technology could also be used to connect mining information to sensors embedded in the railway cars and in the mined materials, thereby improving traceability. Thus, digitalization and blockchain would transform the anthropogenic carbon cycle from an anarchic system into a transparent and well-documented one.

We finally demonstrate how the physical 'resistance' to the mining of carbon-carrying materials embodied in the vast array of railway cars can be enhanced by a virtual resistance. This can be accomplished by coupling the mining of coal, oil, gas and limestone to the creation of cryptocurrency. The generation of fresh cryptocurrency [34] is a computationally expensive process which is referred to as mining in the same way as this term is applied to raw materials. Cryptocurrencies can be designed in such a way that the number of cryptocoins is limited and the computational cost (expressed by the number of binary operations) for each coin increases in a predefined way as the maximum number of coins is approached. Since the computational cost of mining cryptocurrency is directly connected to the cost of computers and electricity, 
the mining process is equivalent to a financial penalty if coupled to the mining of raw materials.

Assuming that we introduce a new cryptocurrency, tentatively called 'Carboncoin', we could use it to increase the cost of GCS as follows. We require that the mining of each unit of coal, oil, gas and limestone must be accompanied by the mining of one Carboncoin. The exact amount of Carboncoins per ton of raw material could be defined in such a way that one Carboncoin corresponds to the amount of raw material that would emit $1 \mathrm{t}$ of $\mathrm{CO}_{2}$ after combustion. We now assume that the Carboncoin-currency is designed in such a way that its number is limited.

It was reported recently $[7,35]$ that humanity is left with approximately 600 billion tons of $\mathrm{CO}_{2}$ to emit if global warming is to be kept below $2{ }^{\circ} \mathrm{C}$. Coupling the mining of raw material to a mandatory mining of Carboncoins would tie the remaining emissions of $\mathrm{CO}_{2}$ to the Carboncoins whose number is limited to a maximum of 600 billion units by the design of a mining algorithm. Under such a scheme, our carbon credit would be automatically limited by the laws of cryptography. The finite amount of cryptocurrency and the high computational power necessary for its mining would increase the GCS far beyond the values listed in Table 1. It is important to note that the current cryptocurrency mining method ('Proof of Work') is criticized for its extensive energy consumption and carbon footprint, see e.g. [36]. However, blockchains do not necessarily need to be based on this algorithm. Less energy-consuming consensus algorithms, such as 'Proof of Stake', could potentially avert an ever-increasing energy demand.

To set the speed of the decarbonization of the global energy system, the mining algorithm for Carboncoins would have to be designed in such a way that the computational cost increases with time so as to limit the anthropogenic emission or carbon dioxide according to the requirements of the corresponding decarbonization scenario. This parameter would have to be set by international agreements.

It should be noted that our concept of Carboncoins is fundamentally different from that of the Climatecoins recently proposed for emission trading. Our Carboncoin serves no other purpose than to provide a reliable evidence of the extraction of a limited amount of carboncarrying material. It should also be emphasized that this concept is easier to verify than climate compensation measures.

Finally, we should discuss some fundamental uncertainties in the implementation of the GCS approach. On the one hand, this concerns the role of producers, who will have to lose most of their business volume in the long term as a consequence of climate targets. GCS could provide financial incentives for producers to adapt and pivot their business cases with the retention of fuels and by participating in the emerging infrastructure business. Given the remaining 600 billion tons of $\mathrm{CO}_{2}$ to emit and a targeted GCS of at least $75 € / \mathrm{t}_{\mathrm{CO} 2}$, an annual financial volume on the order of 1500 billion $€$ can be anticipated on average for the period up to 2050. At the same time, there must also be mechanisms that ensure that a high enough effective carbon price is reached quickly to not exceed the carbon budget, especially at the beginning of the introduction of GCS. This seems necessary because the price elasticity of fossil resource use is unclear in view of existing path dependencies, and the instrument must not lead to a further delay in stringent and effective climate protection. With increasing costs for fossil resources, possibilities will be sought to circumvent the regulations. Therefore, a superior independent organization would have to evaluate and monitor the mechanisms and their effectiveness.

\section{Conclusions}

Our analysis shows that a mandatory on-site storage of carbon-carrying raw materials could in principle achieve a high cost effect, even if there are many question marks about economic and ecological impacts and the concrete feasibility. Such a mechanism therefore has the potential to add an effective surcharge on all subsequent products, covering all sectors of the world economy. Thus, it can increase the effective price of carbon in a similar way as a global carbon tax. However, it encloses the opportunity to trace and verify the cost drivers and the possibility to be organized as a global agreement between citizens and firms. The calculations reveal that only small-scale storage with large material and infrastructural needs is suited to provide a surcharge in the range of $75 € / t$ that is believed to be necessary for effective decarbonization. Compulsory storage can in principle be coupled with blockchain-based smart contracts and a mandatory mining of cryptocurrency.

We have introduced GCS as an exemplary thought experiment focusing on how far investment costs translate into surcharges on the raw materials. Aspects of a practical implementation, verification of effectiveness and economic and ecological implications need further analysis but are beyond the scope of the present paper.

\section{Abbreviations}

$\mathrm{CaCO}_{3}$ : Calcium carbonate; $\mathrm{CNG}$ : Compressed natural gas; $\mathrm{CO}_{2}$ : Carbon dioxide; GCS: Global carbon surcharge; GHG: Greenhouse gases; GWP: Global warming potential

\section{Acknowledgements \\ The authors are grateful to Richard Bamler and Stefan Dech for insightful discussions about satellite imaging.}

\section{Authors' contributions}

AT conceived the concept and formulated the model. MK, KN and TP collected the data and carried out the computations. All authors discussed the results. AT wrote the paper, and all coauthors commented the manuscript. All authors read and approved the final manuscript. 
Funding

None.

\section{Availability of data and materials}

All data used and generated during this study are cited respectively and are included in this published article. The detailed dataset calculated and used for the presentation of the results is available from the corresponding author on reasonable request.

\section{Ethics approval and consent to participate}

Not applicable.

\section{Consent for publication}

Not applicable.

\section{Competing interests}

The authors declare that they have no competing interests.

Received: 8 February 2019 Accepted: 19 January 2020

Published online: 19 February 2020

\section{References}

1. UNFCCC - United Nations Framework Convention on Climate Change (2015) Adoption of the Paris. Agreement. Report No. FCCC/CP/2015/L.9/Rev. 1. [Internet]. Available: http://unfccc.int/resource/docs/2015/cop21/eng/ 109r01.pdf

2. IPCC - Intergovernmental Panel on Climate Change (2014) Climate Change 2014. Mitigation of climate change. Working Group III contribution to the Fifth Assessment Report of the Intergovernmental Panel on Climate Change [Internet]. Available: https://www.ipcc.ch/report/ar5/wg3/

3. Stiglitz JE, Stern N, Duan M, Edenhofer O, Giraud G, Heal G, et al (2017) Report of the high-level commission on carbon prices. [Internet]. Available: https://static1.squarespace.com/static/54ff9c5ce4b0a53decccfb4c/t/59244 eed17bffc0ac256cf16/1495551740633/CarbonPricing_Final_May29.pdf

4. Chapron G (2017) The environment needs cryptogovernance. Nature. 545: 403-403

5. Narayanan A, Bonneau J, Felten E, Miller A, Goldfeder S (2016) Bitcoin and cryptocurrency technologies: A comprehensive introduction. Princeton University Press.

6. Schellnhuber HJ, Cramer WP, editors (2006) Avoiding dangerous climate change. Cambridge University Press.

7. Rockström J, Gaffney O, Rogelj J, Meinshausen M, Nakicenovic N, Schellnhuber HJ (2017) A roadmap for rapid decarbonization. Science. 355(6331):1269-1271

8. United Nations (2017) Reference: C.N.464.2017TREATIES-XXVII.7.d" (PDF). Depositary Notification. [Internet]. Available: https://treaties.un.org/doc/ Publication/CN/2017/CN.464.2017-Eng.pdf

9. Shear MD (2017) Trump will withdraw U.S. from Paris Climate Agreement. The New York Times. 2017 June 1. [Internet]. Available: https://www. nytimes.com/2017/06/01/climate/trump-paris-climate-agreement.html

10. Cline WR (1992) The economics of global warming. Institute for International Economics. ISBN: 9780881321326.

11. Aldy J, Stavins R (2012) The Promise and Problems of Pricing Carbon: Theory and Experience. J Environ Dev 21(2):152-180

12. Spreng CP, Sovacool BK, Spreng D (2016) All hands on deck: polycentric governance for climate change insurance. Clim Chang 139:129 https://doi. org/10.1007/s10584-016-1777-z

13. Nordhaus W (2015) Climate clubs: overcoming free-riding in international climate policy. Am Econ Rev 105(4):1339-1370 https://doi.org/10.1257/aer 1500000

14. UNFCCC - United Nations Framework Convention on Climate Change. Greenhouse Gas Inventory Data. [Internet]. 2014. Available: http://unfccc.int/ ghg_data/items/3800.php

15. Stern N (2007) The economics of climate change: The Stern Review. Cambridge University Press

16. Anthoff D, Tol RSJ (2013) The uncertainty about the social cost of carbon: a decomposition analysis using FUND. Clim Chang 117:515-530

17. Emission Factor Database EFDB. IPCC - Intergovernmental Panel on Climate Change. [Internet]. 2006 [cited 2018 March 29]. Available: http://www.jpccnggip.iges.or.jp/EFDB/main.php
18. The role of gas storage in internal market and in ensuring security of supply. EC - European Commission, Directorate-General for Energy. EUR 2015.1391. [Internet]. 2015 [cited 2018 March 29]. Available: https://ec.europa.eu/energy/ sites/ener/files/documents/REPORT-Gas\%20Storage-20150728.pdf

19. Current state of and issues concerning underground natural gas storage. Staff report. Federal Energy Regulatory Commission (FERC). [Internet]. 2004 September 30 [cited 2018 March 29]. Available:https://www.ferc.gov/ EventCalendar/Files/20041020081349-final-gs-report

20. Facts and figures about the power plant. Trianel Kohlekraftwerk Lünen. [Internet]. 2015 [cited 2018 March 29]. Available: http://www.trianel-luenen.de

21. Government of Gujarat. Establishment of tank farms at PCPIR, Dahej. [Internet]. 2017 [cited 2018 March 29]. Available: https://vibrantgujarat.com/ writereaddata/images/pdf/project-profiles/Tank-Farms-at-PCPIR-Dahej.pdf

22. Proven returns for tank farms and terminals. Siemens. [Internet]. 2017 [cited 2018 March 29]. Available: http://w3.siemens.com/markets/global/en/oil-gas/ Publishinglmages/applications/storage/ Brochure-tank-farm-EN.pdf

23. Güterwagenkatalog Gattung H. DBCargo. [Internet]. 2017 [cited 2018 March 29]. Available: https:/gueterwagenkatalog.dbcargo.com/de/gueterwagenkatalog/detail/ detail/bauart/cd9ec92ef78e9af8ac386286ad941528-/

24. Wagon manufacturing. VTG Waggonbau Graaff. [Internet]. 2016 [cited 2018 March 29]. Available: https://www.waggonbau-graaff.com/

25. On the road - by rail - inter-modal traffic. Feldbinder Spezialfahrzeugwerke. [Internet]. 2017 [cited 2018 March 29]. Available: http://www.feldbinder.com/ en/vehicles 265/

26. Equipment. Seaco. [Internet] [cited 2018 March 29]. Available: http://www. seacoglobal.com/equipment/

27. Technology containers from CARU containers. Caru-Tech. [Internet]. 2017 [cited 2018 March 29]. Available: https://www.caru-tech.com/

28. Frischknecht $\mathrm{R}$, Jungbluth $\mathrm{N}$, Althaus $\mathrm{H}-\mathrm{J}$, Doka $\mathrm{G}$, Dones $\mathrm{R}$, Heck T et al (2005) The ecoinvent database: Overview and methodological framework. Int J Life Cycle Assess 10(1):3-9

29. DigitalGlobe. worldview4. [Internet] 2017. Available: http://worldview4. digitalglobe.com

30. Tozer TC, Grace D (2008) High-altitude platforms for wireless communications. Electronics \& Communication Engineering Journal 13(3):127-137

31. Flyvbjerg B, Bruzelius N, Rothengatter W. Megaprojects and risk: An anatomy of ambition. Cambridge University Press, 2003.

32. World Steel Association. Steel's contribution to a low carbon future and climate resilient societies - worldsteel position paper. ISBN 978-2-930069-83-8, 2019.

33. Andoni $\mathrm{M}$ et al. Blockchain technology in the energy sector: A systematic review of challenges and opportunities. Renewable and Sustainable Energy Reviews, Volume 100, February 2019, 143-174.

34. Nakamoto S. Bitcoin: a peer-to-peer electronic cash system. [Internet]. 2008. Available: www.bitcoin.org

35. Figueres N, Schellnhuber HJ, Whiteman G, Rockström J, Hobley A, Rahmstorf S (2017) Three years to safeguard our climate. Nature. 546:593-595

36. Stoll C, Klaaßen L, Gallersdörfer U (2019) The Carbon Footprint of Bitcoin. Joule 3:1-15 https://doi.org/10.1016/j.joule.2019.05.012

\section{Publisher's Note}

Springer Nature remains neutral with regard to jurisdictional claims in published maps and institutional affiliations.

Ready to submit your research? Choose BMC and benefit from:

- fast, convenient online submission

- thorough peer review by experienced researchers in your field

- rapid publication on acceptance

- support for research data, including large and complex data types

- gold Open Access which fosters wider collaboration and increased citations

- maximum visibility for your research: over $100 \mathrm{M}$ website views per year

At BMC, research is always in progress.

Learn more biomedcentral.com/submission 